\title{
Effectiveness of Facebook in English Language Learning: A Case Study
}

\author{
Qais Faryadi \\ Department of Computer Science, Faculty of Science and Technology, Universiti Sains Islam Malaysia (USIM), Nilai, Malaysia \\ Email: qais@magnesium4you.com
}

How to cite this paper: Faryadi, Q. (2017) Effectiveness of Facebook in English Language Learning: A Case Study. Open Access Library Journal, 4: e4017.

https://doi.org/10.4236/oalib.1104017

Received: October 10, 2017

Accepted: November 6, 2017

Published: November 9, 2017

Copyright $\odot 2017$ by author and Open Access Library Inc.

This work is licensed under the Creative Commons Attribution International License (CC BY 4.0).

http://creativecommons.org/licenses/by/4.0/

(c) (i) Open Access

\begin{abstract}
The prime objective of this research was to investigate whether Facebook helped undergraduate students of Universiti Sains Islam Malaysia (USIM) improve their English language proficiency, critical thinking, comprehension skills, and motivation. A triangulation method (quantitative, qualitative, and descriptive) was employed in the investigation. A total of 900 undergraduate students participated. The 900 participants were first year students from USIM. The instruments used in this research were questionnaires, interviews, and observations. Results from a pre-test and a post-test showed that students who used Facebook i.e. the control group outperformed ( $88.8 \%$ passed) the students who were not exposed to Facebook (60\% passed) in all the three categories. The findings indicated that Facebook indeed helped students to improve their English proficiency, besides learning new words and terminologies. This research offers guidelines to future researchers on the methodology of learning English language and helps them design an effective interactive multimedia learning environment in their classroom. The findings of this research would also contribute to the expansion of the paradigm of Constructivism. The findings of this empirical research could be prototyped for learning other languages in the classroom.
\end{abstract}

\section{Subject Areas \\ Online Social Network Computing}

\section{Keywords}

Facebook, Learning, Teaching, Multimedia, Motivation, English Language

\section{Introduction}

This research was aimed at investigating whether Facebook facilitated learning 
of the English language as well as improve critical thinking, comprehension skills, and motivation to study English. With the increasing popularity of computers and interactive multimedia learning tools, teacher-centered learning should inevitably give way to a more meaningful and enjoyable learning environment. Teachers should also employ technology-intervened teaching methods in the classroom in order to provide opportunities for their students with different learning styles to perform well. Technologically-assisted social media, in fact, paves the way for more exciting and meaningful learning settings [1]. The use of interactive technology such as Facebook offers an alternative way of content delivery in the classroom. Instructors are advised to blend relevant and useful multimedia contents in their instruction to make learning more stimulating, motivating and exciting. More Malaysians now have access to social media and information technology. Even the Malaysian educational system is being reshaped by Information Technology. Multimedia instructional materials to teach the English language are widely available. Unfortunately, a lot of these English teaching materials are not based on scientific research and field-tested paradigm of foreign language acquisition [2] [3].

This research was undertaken based on the supposition that Facebook would motivate and facilitate the learning of the English language by USIM students.

\section{Problem Statement}

The problem investigated in this research was whether Facebook helped USIM undergraduates learn the English language faster and whether Facebook increased their critical thinking, comprehension skills, motivation, and satisfaction.

\section{Research Questions and Hypotheses}

\subsection{Research Questions}

1) Do learners of English language increase their comprehension skills when they use Facebook?

2) What is the level of satisfaction and motivation experienced when using Facebook?

3) Does Facebook assist the development of critical thinking skills?

4) Does Facebook make any significant difference in learners' test scores?

\subsection{Research Hypotheses}

H1: Learners who utilize Facebook increase their comprehension skills.

H2: Facebook users are satisfied and motivated when they use Facebook.

H3: Facebook assists learners improve critical thinking skills.

H4: Facebook makes a significant difference in test scores.

\section{Rationale of the Research}

1) The findings of this research would contribute to the development of a pa- 
radigm of learning, namely Constructivism. The findings of this empirical research could be prototyped for the learning of other languages.

2) This study might offer guidelines for the use of a more viable alternative to the traditional methods of teaching English as a second language in Malaysia.

3) This research would assist the Ministry of Education overcome the shortage of well-trained English language teachers in Malaysia.

4) Interviews, observations, questionnaires and field worksheets from this study would provide valuable information for other researchers in language learning.

\section{Literature Review}

To understand how knowledge transforms, how a learner learns, and how a teacher teaches, it is vital to know how educational psychologists and theorists perceive the knowledge revolution. According to behaviorists, learning happens only by observable behaviors (observe and learn) and is strengthened by reinforcement. The reinforcement can be in the form of reward or punishment. The Behaviorist's theory of rewards is associated with the concept of motivation. Behaviorists believe that punishment can deter undesirable behavior.

Hence, according to behaviorists, man's actions must be controlled as scientists control and train animals.

\subsection{Remarks}

The Behaviorist's theory repudiates the existence of the human mind as a distinct feature in man and animal. To behaviorists, man is like a machine; he can be switched on and off; he has no choice but to adapt to the environment [4]. The theory of behaviorism is, in fact, a simple theory with an extraordinary message: animals learn and so do humans. Behaviorists further claim that we learn because we follow certain accepted universal laws of behavior and discipline. "Foolishness is bound up in the heart of a child; the rod of discipline will remove it far from him" [5].

\subsection{Constructivists}

On the other hand, assume that learning is a hunt for meaning. Learning is mental development. To constructivists, learning is a product of an active process rather than passively waiting to receive it [6]. The purpose of learning is for the individual learner to build her/his own meanings. Piaget, a prominent educational psychologist of the constructivist paradigm, stressed that learners construct knowledge through a rational combination of internal challenges facilitated by forces of the environment [7]. These internal challenges are present in the environment, encouraging us to gain knowledge and to build upon it. To Piaget, humans are always in a state of constant evolution. We learn something new with the help of our past knowledge, and in the process we discover new knowledge [8]. 
Vygotsky, another prominent educational psychologist of the constructivist paradigm, maintains that there is a strong relationship between human beings and the environment. Vygotsky places culture at the center of any cognition. Without society there is no chance for the mind to develop. "Culture can be seen as a way of being that is indexed to the environment" [9]. In other words, culture mediates our mental actions. Vygotsky believes that signs (learning signs), concepts and language guide the behavior of a child. As social beings, children start their interaction with people in their circle as early as the age of two. According to him, when a child is born, the initial function of his/her speech is attuned to social interaction. As such, language acquisition is facilitated when children interact with others [10].

According to Jerome Bruner, a constructivist, the learner is active, constructive, collective, goal-oriented, investigative, and thoughtful [11]. Learning is student-centered and learners construct knowledge through their own investigations. A good learner must take the initiative for self-testing and is constantly checking her/his progress to make sure that learning goals and objectives are met successfully. In a constructivist learning environment, where students are allowed to make their own investigations, they gain better understanding [12]. Bruner emphasizes that when children in their early ages try to roll over, sit down, sit up, walk and fall, they are in fact learning based on their own trial and error.

\subsection{Remarks}

This theory is one of the more pragmatic methods of teaching and learning the English Language. Instructors engage their students in a meaningful dialogue, giving guidance only when necessary. Too much control creates fear, and fear creates an environment that is not conducive to learning [13] [14].

\section{Methodology}

Triangulation (qualitative, quantitative, observation) methods of data collection were adopted to conduct the investigation [15] [16]. The qualitative method was used to collect and analyze data while a quantitative method was used to further strengthen the qualitative data [17]. The independent variable in this research was the method of instruction (Facebook). The dependent variables were the learners' comprehension skills, satisfaction, motivation, critical thinking, and students' test scores. The instruments used to collect data were 1) pre-test and post-test, 2) field observation of learners' facial expression, satisfaction, and motivation in the classroom 3) observation of instructor's (class teachers) concentration and alertness, 4) questionnaires, interviews, and participants' perceptions and opinions. One day before the commencement of the experimentation, the researcher administered a pre-test to evaluate the students' proficiency of the English language. A post-test was conducted after a lapse of four months during which the control group of students utilized Facebook for improving their profi- 
ciency of the English language.

\section{Results}

900 students participated in this study. Based on the interviews, questionnaires and pre- and post-tests, the majority of the students in the experimental group were of the view that Facebook helped improve their English language proficiency as well as critical thinking, comprehension skills, and motivation.

\section{CONTROL GROUP}

PRE-TEST:

The Question: Write an essay of about 550 words describing your purpose of attending an ICT class.

The following are the test scores:

Grades: Pass mark $=50 \%$

Final score in all three Categories (comprehension, motivation, critical thinking)

$\mathrm{N}=250 / 450$ pass $=(55.6 \%)$ pass

$\mathrm{N}=200 / 450$ fail $=(44.4 \%)$ fail

POST-TEST:

The Question: Write an essay of about 550 words describing your purpose of attending an ICT class.

The following are the test scores:

Grades: Pass mark $=50 \%$

Final score in all three categories. (comprehension, motivation, critical thinking)

$\mathrm{N}=270 / 450$ pass $=(60 \%)$ pass

$\mathrm{N}=180 / 450$ fail $=(40 \%)$ fail

\section{EXPERIMENTAL GROUP}

PRE-TEST:

The Question: Write an essay of about 550 words describing your purpose of attending an ICT class.

The following were the results:

1) Comprehension: 35 MARKS $\quad \mathrm{N}=230 / 450$ pass $\quad(51.2 \%$ pass)

2) Motivation and satisfaction: 35 MARKS $N=150 / 450$ pass

(33.3\% pass)

3) Critical thinking: 30 MARKS $\quad \mathrm{N}=120 / 450$ pass $\quad$ (26.6\% pass)

Grades: Pass mark $=50 \%$ Final score: $\mathrm{N}=300 / 450$ pass $=(66.6 \%)$ pass

$\mathrm{N}=150 / 450$ fail $=(33.4 \%)$ fail

POST-TEST:

The Question: Write an essay of about 550 words describing your purpose of attending an ICT class.

The following were their test scores:

1) Comprehension: 35 MARKS $\quad \mathrm{N}=300 / 450$ pass $\quad$ (66.6\% pass)

2) Motivation and satisfaction: 35 MARKS $\quad \mathrm{N}=250 / 450$ pass

(55.5\% pass) 


\section{3) Critical thinking: 30 MARKS $\quad \mathrm{N}=230 / 450$ pass $\quad$ (51.2\% pass)}

Grades: Pass mark $=50 \%$ final score in all three. $\mathrm{N}=400 / 450$ pass $=(88.8 \%)$ pass

$$
\mathrm{N}=50 / 450 \text { fail }=(11.2 \%) \text { fail }
$$

As evident from the scores of the Pre-test and Post-test for the experimental group, students who were exposed to Facebook ( $88.8 \%$ pass $/ 11.2 \%$ fail) (See Table 1) outperformed the students who were not exposed to Facebook (60\% pass $/ 40 \%$ fail) in all the three categories.

\section{Discussion}

This research found that students who utilized Facebook greatly improved their comprehension skills, satisfaction, motivation, and test scores [18]. The findings indicated that Facebook helped to improve critical thinking. Results from the critical thinking component of the post-test showed that the majority of the students in the control group did not do well. Hence, the students in the Experimental group benefited as their English language proficiency was raised because of using Facebook. The main findings from the test results and the interviews with members of the Experimental Group were as follows:

1) Comprehension Skills: Out of 450 students, 430 (95.6\%) students were of the view that they gained new vocabulary from chatting with friends while 20 out $450(4.4 \%)$ were of the view that nothing special happened to them regarding learning the English language.

2) Satisfaction and Motivation: Almost all the students viewed Facebook as a source of motivation for learning the English language. Only 10 (2.3\%) students expressed indifference.

3) Critical thinking: 390 students (87.7\%) said Facebook helped them to improve their critical thinking skills.

4) Final grade: 300 students (66.6\%) indicated that Facebook helped them to acquire English comprehension and vocabulary so that eventually they improved the comprehension and vocabulary section of the post test. However, $150 \mathrm{stu}-$ dents (33.4\%) mentioned that Facebook did not improve their test scores.

\subsection{Effects of Facebook on Learners' Comprehension Skills}

Facebook as a method of teaching English as a foreign language in the classroom should have positive effects on students' comprehension skills. Facebook helps learners by introducing multimedia and pictures and narrating words with

Table 1. Comparison between control and experimental groups.

\begin{tabular}{cccc}
\hline \multicolumn{2}{c}{ Control Group } & \multicolumn{2}{c}{ Experimental Group } \\
\hline Pre-Test & Post-Test & Pre-Test & Post-test \\
\hline $250 / 450$ & $270 / 450$ & $300 / 450$ & $400 / 450$ \\
$(55.6 \%)$ pass & $(60 \%)$ pass & $(66.6 \%)$ pass & $(88.8 \%)$ pass \\
\multicolumn{2}{c}{ Significant $(60 \%)$} & \multicolumn{2}{c}{ Significant $(88.8 \%)$} \\
\hline
\end{tabular}


sound for better visualization. Students learn cooperatively [19]. According to Bruner's Task Focused Model, students learn through action, visual assistance, and critical thinking [20]. They should be engaged in every step of the instruction for better outcomes [21]. As such, when students are fully engaged in reading the materials posted on Facebook, they would make every effort to understand what they read. The improved scores on the comprehension aspect of the test validated the hypothesis $\mathrm{H}^{1}$, that learners who utilize Facebook increase their comprehension skills.

\subsection{Effects of Facebook on Learners' Satisfaction and Motivation}

Results obtained from classroom observations and questionnaires suggested that Facebook motivated the learners to learn and continue learning the English language. Observations by the researcher indicated that learners were very satisfied with Facebook and gained confidence as English language learners [22]. This was evident from their bodily gestures, engagement, and excitement in the classroom. According to Keller's ARCS Model, motivation is an important component of any instructional design [23]. Students learn because they are motivated. Students who are Facebook users are motivated to apply new knowledge to real life as the activities in Facebook are relevant to their everyday activities. This is in conformity with the findings that social media such as Facebook are an excellent method of knowledge transfer [24].

An important discovery from the interviews indicated that students could remember more English vocabulary because the words were repeated many times by their friends. Observations indicated that the learners' attitude towards the learning of the English language using Facebook was very positive [25]. Students seemed excited and happy. Recorded conversations of the students reflected their satisfaction. According to students' gesture, gazing, facial expressions and body language also confirmed their learning pleasure [26]. The classroom observations, as well as improved scores on the motivation and satisfaction aspect of the test validated the hypothesis $\mathrm{H}^{2}$ that Facebook users are satisfied and motivated when they use Facebook.

\subsection{Effects of Facebook on the Learners' Critical Thinking Skills}

Results from this research indicated that Facebook increased learner's critical thinking skills significantly [27]. It should be noted that there was a significant increase in post-test scores of participants the experimental group. Interviews conducted with selected students indicated a significant finding. The majority of the students were of the view that Facebook improved their critical thinking skills and helped them perform better in the post-test. So, there is a correlation between critical thinking and exam grades. Besides improving their English proficiency, students also performed better in their test [28]. The improved scores on the critical thinking skills aspect of the test validated the hypothesis $\mathrm{H}^{3}$, that Facebook assists learners improve critical thinking skills. 


\subsection{Effects of Facebook on the Learners' Overall Test Scores}

The results of this research indicated that Facebook enabled learners to achieve excellent results in their post-test. It is vital to note that there was a significant improvement in the test scores of the experimental group. This is evident from the interviews conducted with selected students. The majority of the students were of the view that Facebook improved their English proficiency and helped them score better results in the post -test. The student interviews as well as the improved overall test scores validated the hypothesis $\mathrm{H}^{4}$, that Facebook makes a significant difference to test scores.

\section{Conclusion}

Results from this research indicated that Facebook provides an environment that is conducive to the learning of the English language. Learners' exposure to Facebook improved students' performance in the post-test. These findings are supported by other studies on multimedia education [29]. Results also suggested that Facebook improved Malaysian learners' attitude, confidence, satisfaction, motivation and perception about learning the English language. As such, this research demonstrated that social media, when embedded with state of the art technology as exemplified by Facebook, indeed helped students to excel in English language learning.

\section{Implications for Educators}

The results in this research revealed that it is crucial to understand how a foreign language, especially the English language, is acquired. To understand how a person learns, the instructor must identify the nature of teaching and learning first before even attempting to design effective instruction. Because technologies and social media, especially Facebook, are redefining our classrooms, educators need to understand and adapt to different pedagogies in order to expand the classroom environment. As such, teachers should design instruction that meet the needs of their learners.

The following are some specific implications of using social media in English language instruction:

1) Facebook reduces stress on the teacher because its environment is friendly, conducive to learning, and is student-centered.

2) Facebook modifies the teachers' job to that of a facilitator, thus allowing her/him to pay more attention to the weaker learners.

3) Facebook reduces disruption in the event of the teacher's absence or change.

\section{Further Research}

This research investigated the role played by Facebook in teaching and learning English as a foreign language to first year students of USIM. Similar investigations should be conducted using students from different academic years to in- 
vestigate the beneficial effects of encouraging learners to use Facebook [30]. Another study should be conducted to investigate the effect of social media such as Facebook on students who are physically disabled to find out how technology-based methodologies can help them learn the English language more effectively [31].

\section{Limitations of the Study}

The benefits of using Facebook cannot be generalized. Further investigations are needed to examine how Facebook and other social media can be exploited for learning not only English, but also other foreign languages. This experimentation was carried out only for a period of four months and the results might have been affected by various factors beyond the scope of this study. Perhaps a longer study period with a larger sample would yield more conclusive results.

\section{References}

[1] Akınoğlu, O. and Eren, C.D. (2013) Effect of Problem-Based Learning (PBL) on Critical Thinking Disposition in Science Education. JEPE, 14, 1353.

[2] Mayer, R.E. (2003) Learning and Instruction. Prentice Hall, Upper Saddle River.

[3] Payne, M. (2007) Foreign Language Planning: Pupil Choice and Pupil Voice. Journal of Education, 37, 89. https://doi.org/10.1080/03057640601179194

[4] Liu, H. and Mathew, R. (2005) Vygotsky's Philosophy: Constructivism and Its Critics Examined. International Education Journal, 6, 386-399.

[5] Wegner, P.D. (2005) Discipline in the Book of Proverbs: To Spank or Not to Spank? Journal of the Evangelical Theological Society, 48, 715.

[6] Colburn, A. (2007) Constructivism and Conceptual Change, Part 2. The Science Teacher. ProQuest Education Journal, 74, 8.

[7] Izzo, M., Langford, B. and Vitell, S. (2006) Investigating the Efficacy of Interactive Ethics. Journal of Education and Practice, 7, 91-103.

[8] Kanuka, H. and Anderson, T. (1999) Using Constructivism in Technology-Mediated Learning: Constructing Order Out of the Chaos in the Literature. ICAAP.

[9] McGlonn-Nilson, K. (2005) Looking Outward: Exploring the Intersections of Sociocultural Theory and Gifted Education. The Journal of Secondary Gifted Education, 17, 48-55. https://doi.org/10.4219/jsge-2005-391

[10] Faryadi, Q. and Zainab, H. (2008) Determining a Theoretical and an Empirical Based Interactive Multimedia Arabic Language Courseware to Teach Arabic as a Foreign Language. Proceedings of Knowledge Management International Conference, Langkawi, Malaysia.

[11] Bishop, C.F., Caston, M.I. and King, C.A. (2014) Learner-Centered Environments: Creating Effective Strategies Based on Student Attitudes and Faculty Reflection. Journal of the Scholarship of Teaching and Learning, 14, 46-63. https://doi.org/10.14434/josotl.v14i3.5065

[12] Chuang, I. (2004) Comparative Assessment of Constructivist and Traditionalist Approaches to Establishing Mathematical Connections in Learning Multiplication. Education, 125, 271.

[13] Qais, F., Zainab, A. and Hamidah, M. (2007) Welcome Constructivism, Bye, Bye Every Ism! The $2^{\text {nd }}$ International Conference on Science and Mathematics Educa- 
tion (CosMEd), Penang.

[14] Ge, X., Chen, C.-H. and Davis, K.A. (2005) Scaffolding Novics Instructional Designers' Problem-Solving Process Using Question Prompts in a Web-Based Learning Environment. Journal Educational Computing Research, 33, 219-248. https://doi.org/10.2190/5F6J-HHVF-2U2B-8T3G

[15] Long, H.Y. (2017) Validity in Mixed Methods Research in Education: The Application of Habermas' Critical Theory. International Journal of Research \& Method in Education, 40, 201-213. https://doi.org/10.1080/1743727X.2015.1088518

[16] Sharp, J.L., Mobley, C., Hammond, C., Withington, C., Drew, S., Stringfield, S. and Stipanovic, N. (2012) A Mixed Methods Sampling Methodology for a Multisite Case Study. Journal of Mixed Methods Research, 6, 34-54.

https://doi.org/10.1177/1558689811417133

[17] Riazi, A.M. (2016) Innovative Mixed-Methods Research: Moving beyond Design Technicalities to Epistemological and Methodological Realizations. Applied Linguistics, 37, 33-49. https://doi.org/10.1093/applin/amv064

[18] Yeung, P.-S., Ho, C.S., Chan, D.W., Chung, K.K. and Wong, Y. (2013) A Model of Reading Comprehension in Chinese Elementary School Children, Learning and Individual Differences, 25, 55-66. https://doi.org/10.1016/j.lindif.2013.03.004

[19] Ebrahim, A. (2012) The Effect of Cooperative Learning Strategies on Elementary Students' Science Achievement and Social Skills in Kuwait. International Journal of Science and Mathematics Education, 10, 293-314.

https://doi.org/10.1007/s10763-011-9293-0

[20] Yang, J.F., Yu, H.J., Gong, C.H. and Chen, N.-S. (2017) Students' Perceptions and Behaviour in Technology-Rich Classroom and Multi-Media Classroom. Eurasia Journal of Mathematics, Science \& Technology Education, 13, 621-647. https://doi.org/10.12973/eurasia.2017.00636a

[21] Chen, H. and Chen, J. (2016) Exploring Reading Comprehension Skill Relationships through the G-DINA Model. Educational Psychology, 36, 1049-1064. https://doi.org/10.1080/01443410.2015.1076764

[22] Chue, K.L. and Nie, Y. (2016) International Students' Motivation and Learning Approach: A Comparison with Local Students. Journal of International Students, 6, 678-699.

[23] Vibulphol, J. (2016) Students' Motivation and Learning and Teachers' Motivational Strategies in English Classrooms in Thailand. English Language Teaching, 9, 64-75. https://doi.org/10.5539/elt.v9n4p64

[24] Chapman, D. and Wang, S. (2015) Multimedia Instructional Tools' Impact on Student Motivation and Learning Strategies in Computer Applications Courses. Journal of Interactive Learning Research, 26, 129-145.

[25] Nenthien, S. and Loima, J. (2016) Teachers' Motivating Methods to Support Thai Ninth Grade Students' Levels of Motivation and Learning in Mathematics Classrooms. Journal of Education and Learning, 5, 250-257.

https://doi.org/10.5539/jel.v5n2p250

[26] Cavus, N. and Ibrahim, D. (2017) Learning English Using Children's Stories in Mobile Devices. British Journal of Educational Technology, 48, 625-641. https://doi.org/10.1111/bjet.12427

[27] Brodin, E.M. (2016) Critical and Creative Thinking Nexus: Learning Experiences of Doctoral Students. Studies in Higher Education, 41, 971-989. https://doi.org/10.1080/03075079.2014.943656

[28] Kabeel, A.R. and Mosa Eisa, S. Abd El-M. (2016) The Correlation of Critical 
Thinking Disposition and Approaches to Learning among Baccalaureate Nursing Students. Journal of Education and Practice, 7, 91-103.

[29] Mayer, E.R. (2003) Nine Ways to Reduce Cognitive Load in Multimedia Learning, Educational Psychologist, 38, 43-52.

[30] Dolean, D.D. (2015) How Early Can We Efficiently Start Teaching a Foreign Language? European Early Childhood Education Research Journal, 23, 706-719. https://doi.org/10.1080/1350293X.2015.1104047

[31] Poon, A.Y.K. and Lau, C.M.Y. (2016) Fine-Tuning Medium-of-Instruction Policy in Hong Kong: Acquisition of Language and Content-Based Subject Knowledge. Journal of Pan-Pacific Association of Applied Linguistics, 20, 135-155.

Submit or recommend next manuscript to OALib Journal and we will provide best service for you:

- Publication frequency: Monthly

- 9 subject areas of science, technology and medicine

- Fair and rigorous peer-review system

- Fast publication process

- Article promotion in various social networking sites (LinkedIn, Facebook, Twitter, etc.)

- Maximum dissemination of your research work

Submit Your Paper Online: Click Here to Submit

Or Contact service@oalib.com 